\title{
AO BARRO VOLTARÁS: REFLEXÕES SOBRE A NASCENÇA
}

\author{
Ana Carolina de Souza Silva ${ }^{1}$ \\ DOI 10.26512/revistacalundu.v4i2.34981
}

\section{Começo}

Mbanda Nzila

Eles queimam a escrita, mas não queimam a oralidade.

Eles queimam os símbolos, mas não queimam os significados.

Eles queimam os corpos, mas não queimam a ancestralidade.

Salve!

(SANTOS, 2019, p. 35)

O trecho do poema de Mestre Nêgo Bispo acima é provocador. Ele me faz pensar nos diversos processos que vivi/vivo direta e indiretamente devido às práticas da colonialidade. Há o que posso explicar e o que sequer posso imaginar. Costumo dizer que essa impossibilidade de comunicar ocorre devido às limitações decorrentes da linguagem; trata-se de golpe de "mestres" impor uma língua a fim de exterminar uma cultura e, em seguida, determiná-la como "a língua", ou seja, uma língua única. O que quero dizer é que há aquilo que sequer sou capaz de dizer, pois me falta...

Permito-me me apresentar. Sou ndumbe da casa Manzo Kalla Muisu, terreiro de candomblé de angola localizado no setor rural Sobradinho dos Melos, pertencente a região administrativa Paranoá-DF. Meu pai de santo é Tatetu Kanamburá, um homem de Kasuté Lembá muito sábio e responsável. Ele, assim como toda a família, me acolheu naquela casa há alguns meses e, desde então, tenho aprendido com as con'vivências.

Digo de antemão que minha intenção não é a de detalhar a tradição do candomblé angolano, tampouco venho teorizá-la. Venho com um propósito de apresentar minha perspectiva de criança ainda não iniciada nessa doutrina que,

\footnotetext{
${ }^{1}$ Universidade de Brasília. Email: css.ana@hotmail.com
} 
conforme Tata nos diz, não se aprende nos livros. Portanto, malembe aos mais velhos caso o que eu diga aqui esteja indevido.

Assim, sendo uma ndumbe recém chegada, reconheço que pode haver diversos equívocos aqui, por isso ensaio essa reflexão. No entanto, me recordo de um recém muzenza, um amigo, que dizia: "você, criança, hierarquicamente não tem muita importância, mas tua fala pode nos trazer/lembrar algo importante, justamente por perceber tudo pela primeira vez”. À vista disso, meu desejo é de transgredir. Por associação, teço uma rede que propõe minhas vivências e aquilo que mestres e mestras como Bispo dos Santos, Ailton Krenak, Beatriz Nascimento, minha avó e outras e outros mais velhos já discorriam.

\section{Meio}

Pois bem, era dia 12 de outubro no calendário gregoriano. Nesse dia, aqui no Brasil, temos o feriado em comemoração ao dia de Nossa Senhora, e também ao dia das crianças. Os nossos referenciais, como sempre, são capitalistas, uma vez que dia das crianças é o dia de comprar brinquedos e gastar dinheiro em parques e ambientes de recreação. Nossa sociedade modernizada não é capaz de celebrar as crianças como possibilidades de cura para o futuro; pelo contrário: a data é um reforço das práticas de consumo exacerbado. Próximo a data há um grande investimento em publicidade a fim de alcançar o interesse dos pequenos com parafernálias de plástico - tudo isso me faz rememorar a crônica e a bola de Veríssimo.

Ademais, o dia de Nossa Senhora é um feriado católico. Lembremos que o país é laico, mas sabemos que, entre outras coisas, essa é só mais uma formalização; a nossa burocracia, cheia de seus rococós, serve, na verdade, para manter o estado de coisas. O Estado junto à modernidade e suas ordens políticas e econômicas não prioriza a verdade, mas a conveniência. É por isso que descaradamente o país permanece sob grande influência euro-cristã.

Pois bem, estamos no terreiro e, nesse momento, Pai Lua Branca começa os rituais. Ele é um caboclo encantado, o que significa que, conforme ele mesmo diz, esteve em terra e um dia não pisou nela mais. Encantado é esse ser que nem vive, nem morre, mas se encanta e faz história nas histórias dos outros a partir de suas próprias histórias. 
Relembro bem! Ele sabe e compartilha o conhecimento de que nada nos impede de sermos devotos de Maria Padilha e de uma santa; um boiadeiro e Santo Antônio; tudo ao mesmo tempo. Sua fala vai de encontro a uma das maiores referências intelectuais vivas que acredito termos no Brasil. Não o chamarei de intelectual negro, pois ele mesmo não admitiria isso. Ele é um ancião, alguém que veio antes, alguém que teceu e desteceu muitas redes e, por isso, hoje tem muito a ensinar. O Mestre Antônio Bispo dos Santos, quilombola e morador da comunidade Saco do Curtume, no Piauí, evoca sobre a potência do contracolonialismo, essa força que nos permite ir além das nossas próprias cosmossensações. A epistemóloga Oyěwùmí (1997) retrata bem o termo ao cunhá-lo, definindo enquanto "um modo inclusivo de descrever a concepção do mundo por diferentes grupos" (p. 2-3).

Isso porque somos capazes de ter conhecimento do mundo para além da racionalidade advinda da modernidade. Enxergamos para além da visão positivista, ouvimos para além de nosso aparelho auditivo, dizemos muito mais com nossos corpos que com nosso aparelho fonador. Há algo além que permanece tradicionalmente em nossa memória e, por isso, cosmossentimos. O próprio Mestre Bispo nos lembra de como tivemos a capacidade de ter adicionado em nossa percepção cósmica a crença do colonialista. Isso só foi possível, pois somos povos plurais. O colonialista é monoteísta, nós não.

Pois bem! Esse encantado, Pai Lua Branca, transcende os limites do que se imagina de um terreiro. Isso porque, curiosamente ou não, é extremamente católico e devoto de Nossa Senhora Aparecida, de modo que, em todo 12 de outubro, um terço é rezado em homenagem à santa. É Mestre Bispo dos Santos que lança crítica aos saberes lineares e monoteístas em oposição a nós, politeístas, ao dizer que:

Esses saberes são diferentes, por quê? São saberes de cosmologias diferentes. O euro-cristão-colonialista-monoteísta, por ser monoteísta, pensa de forma linear. Ele só tem um deus. Só olha na direção daquele deus, em uma direção: é mono. É vertical, é linear, não tem curva. Ele pensa e age assim. O povo dito contracolonialista - aqui nos autonomeamos e os nomeamos também - tem vários deuses e várias deusas. E eles ainda doaram o deus deles para nós: vivem insistindo para dar seu deus para nós. Mas qual é o deus que eles querem dar? Um deus colonizado (SANTOS, 2019, p.26).

O filósofo Luís Saraiva, ao retratar os Encantados do Tambor de Mina, relata que um Caboclo "participa de dois mundos e pode até ser cristão" (SARAIVA, 2020, 
p.22); depois complementa que "é aqui que mais uma vez a nossa Linguagem precisa gingar para entender o que está se fazendo presente" (idem). Em consonância, Mestre Bispo conclui: o que demonstra se um povo está dominado/colonizado ou não é a forma como se porta. Logo, se o Caboclo é católico ou não, torna-se o menor dos "problemas" em nosso terreiro.

Mais uma vez me recordo dos relatos de Saraiva (2020) e o Tambor de Mina nas festas de São Pedro e São Marçal presentes na pesquisa do intelectual. Segundo Saraiva o código que é detectado nas festas é euro-cristão, mas a essência das celebrações é afro-pindorâmica-pagã-politeísta. Tudo isso só é possível quando reconhecemos a pluralidade dos saberes orgânicos (SANTOS, 2019) presentes nos calundus, nos quilombos, na capoeira, no samba e em tudo que gira. Tudo isso só é possível quando o mais novo permite olhar para o mais velho e encontrar nele uma sabedoria viva. Assim,

Eu não preciso de Karl Marx e de outros acadêmicos: preciso de minha geração avó, aquela que veio antes de mim e que me move. Essa lógica é organizada em começo, meio e começo. Minha geração avó é começo, minha geração filha é meio e minha geração neta é começo de novo (SANTOS, 2019, p.27).

Saraiva estende essa sabedoria ao Caboclo, ao tratar "aquilo que o colonialismo e suas estratégias de submissão do Ser-poli buscou reduzir em conceitos mono as multiplicidades que compõem o ser-supravivente". O genocídio só se torna tão presente devido à fragilidade do colonizador.

A ideia da transfluência a qual se propôs Mestre Bispo dos Santos não é muito diferente do que falou Ailton Krenak em A vida não é útil (2020). Krenak é uma liderança, um mestre, um disseminador de saberes da contemporaneidade; ele sabe que é possível ouvir a voz do rio, das montanhas, da floresta. Fico honestamente encantada em como suas palavras parecem ser aquilo mesmo que Mestre Bispo nos fala, ou seja, ideias que transfluem. Tudo isso me leva a crer que, de fato, estamos em um momento de nossa contemporaneidade que, se continuarmos levando adiante ideias arcaicas e a caminho da falência como as de Platão e Kant, continuaremos regredindo. Os saberes reais e relevantes não estão em livros clássicos, mas no conhecimento passado por gerações de nossos ancestrais da terra e nossos ancestrais africanos. 
Mestre Bispo dos Santos nos diz que "nosso olhar está voltado para a beleza [...] Assim como a água transflui, por baixo da terra ou pelo ar, nós transfluímos pela cosmologia e pela cultura" (SANTOS, 2019, 24). Foi transfluindo com nossos ancestrais da terra que sobrevivemos diante da extorsão colonialista. Quando volto ao terreiro, volto a aprender a base. Agradeço aos meus antigos.

Sendo uma profissional da linguagem, aprendo a ensinar que a linguagem é a habilidade que se restringe aos seres humanos de comunicarem-se por meio de uma língua. Língua será um sistema constituído de signos vocais (com exceção das línguas de sinais) utilizados em dada comunidade linguística (MARTELOTTA, 2016). Desde Saussure, o pai da Linguística, é dito que a linguagem é uma habilidade exclusivamente humana, mas tenho uma forte tendência em desacreditar nesse princípio básico dessa ciência.

Lembro de Altaci Rubim, mulher indígena do povo Kokama. Ainda na época do mestrado, estava eu atuando enquanto sua estagiária na disciplina "Introdução à Linguística" na Universidade de Brasília. Diante problematizações que permeiam as diversas correntes linguísticas, a Professora Altaci nos diz: “Gente, eu ensino isso que é programado, mas honestamente não consigo acreditar. A Linguística diz que a linguagem é exclusivamente humana, mas quando o pássaro pia, eu sei o que diz. Eu converso com o pássaro". Não posso deixar de revelar o meu estado de choque no momento. Altaci declaradamente foi de frente com o princípio básico da Linguística e, honestamente, foi ótimo ouvir algo tão real.

Tiradas todas as barreiras do positivismo que ainda pairam nas ciências firmemente, Altaci conseguiu simplificar para mim o conhecimento de algo que tem feito cada vez mais sentido na vivência do terreiro. Quando entro no terreiro e peço licença a Pambu Njila, eu me comunico com o guardião que, desde a "minha decisão" de ir ao terreiro, autorizou que eu estivesse lá. Quando, de pés descalços, lavo meu corpo e meu mutuê com kijauá, me comunico com as ervas que preparam meu corpo e tiram qualquer carrego que possa obstruir o ngunzo que receberei. A bênção que peço de meu Pai ao mais novo é mais do que uma bênção concedida por aquele ser materializado, pois tenho a cosmossensação que toda uma herança de seres está presente no ato. $\mathrm{O}$ tambor que toca se comunica com a entidade; a entidade autoriza que as mãos de toque dos Tatas toquem para ela. Quando eu rodo no terreiro, minha dança é a comunicação sagrada. A galinha comunica-se com todos nós; ela tem o propósito de uma obrigação, de uma missão divina; ela sabe para que veio; ela é sagrada por 
alimentar uma energia sagrada, portanto, não sou melhor que ela, uma vez que "os outros seres são junto conosco" (KRENAK, 2020, p. 71).

Aliás, é a partir do alimento que me comunico com minhas entidades. Recordome do dia que fui até minha casa a fim de realizar um fundamento direcionado a Ndanda Lunda, Nkise que representa as águas doces, a fertilidade e outras coisas mais que só saberei vivendo o terreiro. Eu estava gestante, na época, e esse fundamento foi solicitado por uma entidade. Bem, se a comunicação com Nkise se dá pelo alimento, é por isso que o alimento é tão sagrado para nós. Tatetu Kanamburá disse ao final "é de Ndanda Lunda, essa menina tua; ela vai mamar muito, você terá muito leite". E assim foi. E assim é. Oferto alimento, recebo alimento, dou alimento, e tudo circula. Segundo Saraiva, "nossos mortos sentem fome. Iku também come" (SARAIVA, 2020, p. 20). A isso, o autor chamou de "Filosofia da Fome" ao dar-se conta do "alimentar e do fazeralimentar" presente nas festas negras (idem).

Toda a resistência de nossas tradições me faz pensar no que chamarei de metafísica do quilombismo que atravessa os espaços pretos. Pareceu e ainda parece um atrevimento o que Abdias Nascimento dizia desde a década de 70, mas seus saberes transfluem na sabedoria de Mestre Bispo. O quilombismo é a força motriz do contracolonialismo. Em síntese, se o quilombismo se apresenta nas formas associativas que desempenham "um papel relevante na sustentação da continuidade africana", temos, por excelência, uma prática contracolonial, uma vez que não permite que o colonialismo adentre os espaços de resistência.

"Quem deve desmanchar o colonialismo é quem tentou colonizar", já dizia Mestre Bispo (2019, p. 24), "então devemos contracolonizar: impedi-los de fazer" (SANTOS, 2019, p. 25). Vejamos: essas associações formaram e ainda formam "uma unidade, uma única afirmação humana, étnica e cultural, a um tempo integrando uma prática de libertação e assumindo o comando da própria história" (NASCIMENTO, 2019, p. 281). É como Beatriz Nascimento, grande historiadora brasileira, já dizia, que "os homens e seus grupamentos, que formaram no passado o que se convencionou chamar 'quilombos', ainda podem e procuram fazê-los". O quilombo passa a ser, nesse sentido, a práxis contracolonial.

Mestre Bispo dos Santos reconhece essa práxis nas favelas. Para ele, a favela não é a margem do centro, mas uma centralização em si mesma. Para ser margem, pressupõe-se que faça farte, mesmo que minorizada, de um centro; mas o que percebemos nas comunidades faveladas é que, não fosse a força comunitária, não 
haveria existência. O centro centralizador e dominante não passa de uma parte opressora do qual procuramos nos esquivar para não morrer (de fome, de bala, de depressão que seja). "Comunidade é feita de pessoas e essa sociedade é feita de posses" (SANTOS, 2019, p. 31). Enquanto mulher negra que não está no centro de dominação, me sinto em comunidade em minha favela, em meu terreiro, em meus quilombos.

Nesses espaços, sinto que eu e minhas famílias "andamos em constelação" (KRENAK, 2020, p. 39). Especificadamente no terreiro, tenho meu Pai e irmãos, mais velhos e mais novos. Tenho outros Pais, e muitas Mães que, como Mestre Bispo disse, carregam "um saber ancestral que nos ensina" (SANTOS, 2019, p. 32). As makotas sempre sabem o que fazer com as crianças. Eu sou uma criança. E minhas crianças estão no terreiro. E sempre há remédio para tudo. Para o menino que não tem obedecido, benzimento e água de canjica no mutuê. O peito empedrou? Repolho. Umbigo estufado? Cueiro e botão! Dor de cabeça? Tome esse chá e cubra esse mutuê. E todos, absolutamente todos, cuidam de minhas crianças, cuidam de mim, que sou uma criança. E assim vamos rodando.

Se sou criança, há ainda mais segredo. "Não olhe para o quartinho que você não tem idade para isso". "Não fique aqui dentro". "Use sua cinta". "Não pode deixar comida no prato". "Não pode roer osso". "Mulher não pode fazer isso". "Homem não pode fazer aquilo”. E por quê? Só saberei vivendo, porque a tradição é viva e orgânica.

Francamente, não há feminismo europeu que me faça crer que é um desprestígio estar na cozinha quando estou no terreiro. Dar e receber o ngunzo que o alimento sagrado me proporciona é uma sensação de fazer parte do todo. Aliás, ainda sobre o quilombismo no terreiro, esse espaço contracolonial, penso sobre os hábitos alimentares. Ao contrário do que dizem os radicais veganos, nosso consumo de carne é sagrado. Diferente dos moldes de produção desenfreados, a alimentação é um ato de sacralização. Dispensar a carne do bicho ofertado ao Sagrado é, no mínimo, uma afronta. Me lembro de uma experiência de Mestre Bispo dos Santos:

Outro dia um homem me perguntou, em uma fala que fiz em Belo Horizonte, o que eu achava sobre a alimentação dos terreiros no que diz respeito ao sacrifício dos animais. Quando fui responder, disse a ele uma coisa que eu nunca tinha feito, mas que podia poderia fazer. $\mathrm{Eu}$ disse a ele: "Estou em Minas Gerais. Aqui vocês adoram um chouriço. E terça-feira irei no terreiro de Pai Ricardo e beberei sangue e cachaça com Exu. $\mathrm{O}$ animal que vai ofertar o sangue para bebermos morreu, mas o animal do chouriço também morreu. Portanto, a diferença não está em sacrificar o animal, mas no paladar. A gente 
gosta de sangue com cachaça como vocês gostam de chouriço!". Isso é o que eu chamo de pedagogia do impacto, que aprendi com o Mãe Joana (SANTOS, 2019, p. 32).

Seguimos rodando. De acordo com Mestre Bispo,

o deus deles é do milagre. Os nossos, do feitiço. Eles deram o deus deles para nós. Nós 'aceitamos'. E ajeitamos agora. Temos os nossos e o deles. E assim, ou ajeitamos as coisas pelo milagre ou pelo feitiço (SANTOS, 2019, p.28).

Ao contrário dos saberes coloniais, com princípios individualizados e singularizados, acreditamos na continuidade, no compartilhamento, na multiplicação. $\mathrm{O}$ colonizador pensa de forma tão una a ponto de acreditar que, para ser feliz, precisa não ter filhos.

Por sua vez, atravessados por uma cosmossensação afro-pindorâmica, verificamos que ter filhos é uma bênção, é próspero. Mas não posso deixar de mencionar que, embora, às muitas vezes, nos deparamos felizes com o nascimento de um/a muzenza, em contraposição, parir no mundo civil parece sinônimo de uma vida que se acabou. Permito-me problematizar a alegorização que se faz de nossos saberes. É preciso viver o terreiro para além do terreiro ou acabaremos por colonizar esse espaço contracolonial.

Outro processo alegorizante que percebo está na prática de respeito aos mais velhos: ela também deve estar para além dos terreiros. Aquela preta velha, seja ela sua vizinha ou sua avó, ela que muitas vezes se senta quieta, observadora, calada, tranquila; ela que se inquieta e anda para todos os lados, cuidando de todos, mesmo já andando curvado; ela que simplesmente está; ela também é minha mais velha. O terreiro não é lugar de fetichização, mas de retorno, de aprendizado. O que faz com que a ancestralidade seja ovacionada se o respeito à avó, à mãe é negligenciado? Me pergunto: tua ancestral mais próxima é Kayaya? Que sociedade é essa que, enquanto falamos em ancestralidade, não somos capazes de enxergar nossos velhos?

Antes de me questionar sobre tudo isso, ali, em meados dos anos $2017 \mathrm{eu}$ escrevia um poema. O trânsito das palavras em transe-lembrança se materializara nos versos abaixo: 


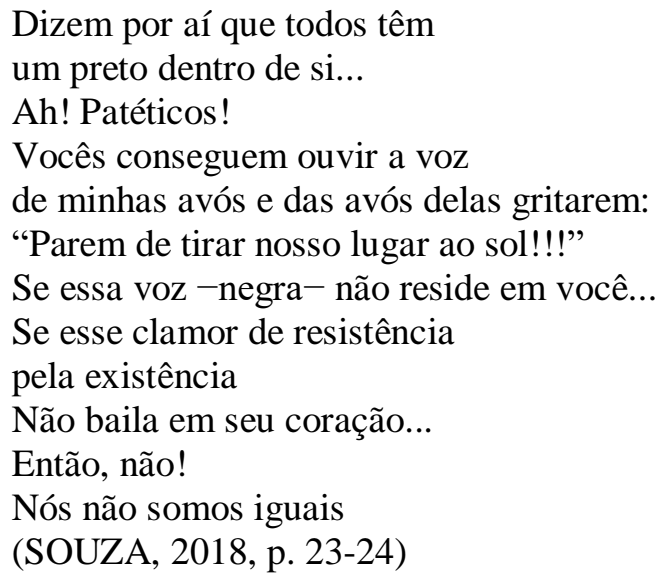

Essas avós são várias; são mulheres comunicadoras que me ensinam mesmo quando estão caladas. Eu as observo com a destreza das mãos que falam tanto. São receitas, costuras, rezas, manias, garrafadas, plantações; são matanças de galinha, feituras do sabão; é o bate-bate do pilão, a técnica de enrolar folha de bananeira; são os diversos espaços de resistência nessa terra em diáspora. Como diz meu irmão de santo, "o conhecimento só é válido quando é passado para frente". Por isso estamos sempre ganhando, pois "a colonização não é um fato histórico, é um processo histórico", logo, não perdemos ainda (SANTOS, 2019, p. 24). Nossos saberes estão vivos nas mãos de nossas mais velhas e mais velhos, basta observar com respeito.

\section{Abre-te campo formoso \\ Abre-te campo formoso \\ Cheio de tanta alegria \\ Ô cheio de tanta alegria \\ (Canção de Caboclo)}

Com essa canção de caboclo vou encaminhando mais algumas reflexões antes de ir ao começo de novo. Sim, aquele ciclo que Mestre Bispo já dizia.

Bem, eu amo dançar. É um poder natural. Acontece um verdadeiro estado transeunte em que vou sem ir. Estou sem estar. A dança me liberta dos carregos também. A mão de toque bate na pele do bicho no tambor e abre caminhos. Nossa música é a louv'ação de chamamento ao encantamento. Dança, gira, ginga, vira, desvira e poeira sobre à medida que os pés pelados batem na terra seca do barracão. No meio de tanto suor, poeira, cura e alegria evoco Saraiva ao questionar "Será se aqui todo mundo é caboclo?" (SARAIVA, 2020, p.19). Capaz. E eu não me canso. As mãos que tocam 
tampouco. Todos em transe. Tanta alegria! Cantamos. Hampatê Bá ilustra bem as cosmossensações do que, com licença poética, chamarei de dança en 'cantada ao dizer que

Nas canções rituais e nas fórmulas encantatórias, a fala é, portanto, a materialização da cadência. E se é considerada como tendo o poder de agir sobre os espíritos, é porque sua harmonia cria movimentos, movimentos que geram forças, forças que agem sobre os espíritos que são, por sua vez, as potências da ação (HAMPATÊ Bá, 1997, p. 173).

O terreiro é o lugar que busco uma memória a partir das vivencias. É a terra boa para o banzo, é o retorno. É o caminhar para trás; é a tentativa de achar uma luz que desobstrua o esquecimento, a pressão alta, a loucura que o colonialismo me empurra. Busco entrelaçar meu corpo à memória e identidade fragmentados em mim. Busco referenciar e reverenciar uma verdade. Eu morro em quase tudo que estive para finalmente encontrar espaço em ser. O lugar para o princípio é a iniciação. Busco nesse quilombo o nascimento. Esse nascimento pode ser o que Beatriz Nascimento chamou de Orí, no momento que o compreende enquanto "a identidade individual, coletiva, política, histórica” (NASCIMENTO, 1989 apud RATTS, 2006, p. 65). Dessa maneira,

toda dinâmica desse nome mítico, oculto, que é o Ori, se projeta a partir das diferenças, do rompimento numa outra unidade. Na unidade primordial que é a cabeça, o núcleo. O rito de iniciação é um rito de passagem, de uma idade para outra, de um momento pra outro, de um saber pra outro, de um poder atuar para outro poder atuar (NASCIMENTO, 1989 apud RATTS, 2006, p. 63).

Evoluir dói. Sair da ignorância dói. Entender dói. Não entender dói. Sozinha dói. Junto, mais ainda. Morrer dói. Nascer, também. E a dor evolui. Eu quero voltar. Para a base. Para o barro. Eu quero nascer de novo.

\section{Começo de novo}

Como Mestre Bispo falou, o colonialista nos denomina a fim de nos enfraquecer com palavras vazias. Porém, em nossa atuação contracolonial de resistência, sabemos ser necessário não alegorizá-la e compreendê-la para além das rodas de samba, rodas de capoeira e terreiros. Sabemos que essas giras se estendem aos quintais, cortiços, aglomerados, batalhas de rap, slams, feiras livres e outros potenciais quilombos os quais falavam Beatriz Nascimento e Abdias Nascimento e que, atualmente, também trata 
Mestre Bispo dos Santos ao falar de contracolonialidade. Os atos contracoloniais de resistência estão em cada família ancestral remanescente de uma prática afropindorâmica. É a metafísica do quilombismo.

Tratando de meu lugar enquanto pensadora, verificamos que as terminologias, de fato, são lugares políticos de dominação. O que o colonialista faz logo ao chegar em terras invadidas? Impõe sua língua e cultura a partir da força bruta. Assim sendo, é uma guerra desleal, seja pelas forças, seja pela intenção. Mas nossa capacidade de expansão, de transgressão, de transfluência é tamanha que continuamos diante disso. Ou seja, de que vale satisfazer o ouvido do colonialista dizendo que cultuo Jesus se, no âmago, vivo Lembá. Ouço, nessa reflexão, a voz de Bethânia: "Quanto nome tem a rainha do mar / Ndanda Lunda, Janaína, Marabô, Princesa de Aiocá / Inaê, Sereia, Mucunã, Maria, Dona Iemanjá”. Eu cultuo as águas do mar, sendo, por hora, essa imensidão marítima.

Nossas palavras são vivas, pois "somos integrados com a vida" (SANTOS, 2019, p. 25). Por mais que sejamos obrigados a cultuar o deus monoteísta e reconhecer em Lembá um Jesus Cristo, "chega um tempo que essa palavra nos serve, porque ela cria força, porque ela nos move, anda com a gente. Nossa ancestralidade entra nessa palavra e a movimenta a nosso favor" (idem).

Por fim, acredito que seja o que Hampaté Bâ já dizia:

\begin{abstract}
Deve-se ter em mente que, de maneira geral, todas as tradições africanas postulam uma visão religiosa do mundo. O universo visível é concebido e sentido como o sinal, a concretização ou o envoltório de um universo invisível e vivo, constituído de forças em perpétuo movimento. No interior dessa vasta unidade cósmica, tudo se liga, tudo é solidário, e o comportamento do homem em relação a si mesmo e em relação ao mundo que o cerca (mundo mineral, vegetal, animal e a sociedade humana) será objeto de uma regulamentação ritual muito precisa cuja forma pode variar segundo as etnias ou regiões (HAMPATÉ BÂ, 2010, p. 173).
\end{abstract}

Pois bem, era dia 12 de outubro no calendário gregoriano. Nesse dia, aqui no Brasil, temos o feriado em comemoração ao dia de Nossa Senhora, e também ao dia das crianças. Nesse dia, Pai Lua Branca batizou minha mais nova. Ela tinha 45 dias em terra, apenas. Embora nunca tivesse presenciado um batizado antes, sei que aquele ritual ocorrera aos moldes católicos. Um encantado incorporado em Tata Kanamburá dentro de um terreiro angola batizando, aos moldes católicos, a minha criança... Beleza que transflui e nada mais. Apesar de tudo, continuamos rodando. 


\section{Referências}

HAMPATÉ Bâ, Amadou. A Tradição Viva. In: Ki-Zerbo, Joseph. História geral da África I: Metodologia e pré-história da África. Brasília: UNESCO, 2010. p. 167- 2012.

KRENAK, Ailton. A vida não é útil. São Paulo: Companhia das Letras, 2020.

MARTELOTTA, Mario Eduardo. Manual de Linguística / organizador Mario Eduardo Martelotta. São Paulo: Contexto, 2016.

NASCIMENTO, Abdias. O quilombismo: documentos de uma militância panafricanista. 3. ed. rev. São Paulo: Editora Perspectiva; Rio de Janeiro: Ipeafro, 2019.

NASCIMENTO, Maria Beatriz, 1942-1995. Beatriz Nascimento, Quilombola $e$ Intelectual: Possibilidades nos dias de destruição. Diáspora Africana: Editora Filhos da África, 2018.

OYEWÚMÍ, Oyèrónké. The invention of women: making an African sense of western gender discourses. University of Minnesota, 1997.

RATTS, Alex. Eu sou atlântica: sobre a trajetória de Beatriz Nascimento. São Paulo: Imprensa Oficial, 2006.

SANTOS, Antônio Bispo. As fronteiras entre o saber orgânico e o saber sintético. In: Organização OLIVA, Anderson Ribeiro...[et al]. Tecendo redes antirracistas: Áfricas, Brasis, Portugal. Belo Horizonte: Autêntica Editora, 2019. p.23-35.

SARAIVA, Luís Augusto F. Ubuntu e a Metafísica Vodum: o pensar filosófico a toques de tambor de mina. Belo Horizonte, MG: Letramento, 2020.

SOUZA, Carolina. Lembranças Ancestrais. In.: Lembranças Ancestrais / Ana Carolina de Souza Silva. Brasília: AUA Editorial, 2018.

Recebido em: 02/11/2020

Aceito em: 16/12/2020 